\title{
Evaluation of Escherichia coli 0157:H7 Growth Media for Use in Test-and-Hold Procedures for Ground Beef Processing ${ }^{\dagger}$
}

\author{
MICHAEL N. GUERINI,* TERRANCE M. ARTHUR, STEVEN D. SHACKELFORD, AND MOHAMMAD KOOHMARAIE
}

\begin{abstract}
U.S. Department of Agriculture, Agricultural Research Service, Roman L. Hruska U.S. Meat Animal Research Center, Clay Center, Nebraska
\end{abstract} 68933-0166, USA

MS 05-436: Received 31 August 2005/Accepted 12 January 2006

\begin{abstract}
Since the mid-1990s, the beef industry has used a process called test and hold, wherein beef trim and ground beef are tested to keep products contaminated with Escherichia coli O157:H7 out of commerce. Current O157:H7 detection methods rely on a threshold level of bacterial growth for detection, which is dependent on the growth medium used. Twelve media were examined for growth and doubling time: buffered peptone water (BPW), SOC (which contains tryptone, yeast extract, $\mathrm{KCl}, \mathrm{MgCl}_{2}$, and glucose), buffered peptone water plus SOC (BPW-SOC), Bacto-NZYM, RapidChek E. coli O157:H7 medium, BioControl EHEC8 culture medium, Neogen Reveal for E. coli O157:H7-Eight Hour medium (Neogen Reveal 8), BAX System medium for E. coli O157:H7 (BAX), BAX System medium for E. coli O157:H7 MP (BAX-MP), modified E. coli broth, nutrient medium, and tryptic soy broth (TSB). All media were tested at 37 or $42^{\circ} \mathrm{C}$ under static or shaking conditions. The eight media with the highest total CFU per milliliter and most rapid doubling times were BPW-SOC, NZYM, RapidChek, EHEC8, Neogen Reveal 8, BAX, BAX-MP, and TSB. The ability of these eight media to enrich E. coli O157:H7 in ground beef was further evaluated through time-course experiments using immunomagnetic separation. Of these media, TSB was the easiest to prepare, had a wide application base, and was the least expensive. In the test-and-hold process, the normal ratio of medium to product is 1:10. In this study, a 1:3 ratio worked as well as a 1:10 ratio. Processors using test-and-hold procedures could use 1 liter of TSB to enrich for E. coli $\mathrm{O} 157: \mathrm{H} 7$ in a 375-g sample instead of the usual 3.375 liters, thus saving reagents, time, and labor while maintaining accuracy.
\end{abstract}

The bacterial pathogen Escherichia coli O157:H7 has been a concern to the meat processing industry for the last 20 years. In the early 1980s, cases of hemorrhagic colitis caused by E. coli O157:H7 were associated with consumption of undercooked ground beef (15) and in 1992 and 1993 a ground beef-related O157:H7 outbreak caused hundreds of illnesses and four deaths (17). In response to these events, the U.S. Department of Agriculture Food Safety and Inspection Service (FSIS) declared E. coli $\mathrm{O} 157: \mathrm{H} 7$ an adulterant in ground beef (16). In the mid-1990s, the beef industry responded to the safety concerns surrounding $E$. coli $\mathrm{O} 157: \mathrm{H} 7$ contamination in ground beef and implemented a process called test and hold, in which a processor samples the trim (the raw material used to make ground beef) or the ground beef, enriches bacterial cultures for growth in bacterial media, and then tests the enrichment for the presence of $E$. coli $\mathrm{O} 157: \mathrm{H} 7$ (7, 10). The product does not enter into commerce unless the sample contains no detectable E. coli $\mathrm{O} 157: \mathrm{H} 7$. This process is extremely expensive and time-consuming for the industry, yet test-and-hold procedures in conjunction with other practices have been extremely effective in enhancing the safety of ground beef products, as noted by dramatic reductions in the number of samples testing positive for E. coli $\mathrm{O} 157: \mathrm{H} 7$ in the FSIS

\footnotetext{
* Author for correspondence. Tel: 402-762-4226; Fax: 402-762-4149; E-mail: guerini@email.marc.usda.gov.

$\dagger$ Mention of trade names or commercial products in this article is solely for the purpose of providing specific information and does not imply recommendation or endorsement by the U.S. Department of Agriculture.
}

verification program (11). These procedures provide insurance for both beef processors and their customers, with the ultimate beneficiary being the consumer.

An effective test-and-hold program depends on highly accurate methods of testing ground beef for E. coli O157: H7. Optimization of three testing attributes, i.e., detection time, specificity, and sensitivity, is critical to the success of such programs. Numerous products are available for endpoint testing of ground beef bacterial enrichment cultures, and some of those tests were recently studied by our group to determine the efficacy of these methods for detecting $E$. coli $\mathrm{O} 157: \mathrm{H} 7$ in ground beef (1). Because ground beef is a highly perishable product, the testing methodology used must be as rapid as possible (turnaround time of less than $12 \mathrm{~h}$ ). To achieve rapid results, the bacterial growth medium used in the test-and-hold procedure needs to provide a growth environment that allows for rapid doubling of $E$. coli $\mathrm{O} 157: \mathrm{H7}$ in ground beef. In work presented here, 12 growth media were evaluated. The optimal growth conditions for E. coli O157:H7 were determined for each type of medium based on total CFU per milliliter at $6 \mathrm{~h}$ of growth and a doubling time between 3 and $6 \mathrm{~h}$. A 6-h time period for growth was selected to demonstrate that certain media could promote robust growth, thereby allowing a sample to be collected, enriched, and tested for the presence of E. coli $\mathrm{O} 157: \mathrm{H} 7$ within an 8-h work shift. In addition, the efficacy of reducing the volume of medium required for testing a 375-g sample of ground beef was examined. 


\section{MATERIALS AND METHODS}

Bacterial strains. Seven strains of E. coli O157:H7 were used in these studies. Two phenotypically marked strains were used for experiment protocol 1. Strain 131AC1 $(2,4)$ was made resistant to $50 \mu \mathrm{g} / \mathrm{ml}$ nalidixic acid by serial passage in the presence of increasing concentrations of nalidixic acid. This resistant strain was designated $131 \mathrm{ACl}\left(\mathrm{Nal}_{50}\right)$. The other strain was an $E$. coli $\mathrm{O} 157: \mathrm{H} 7$ bovine isolate transformed with a constitutive plasmid-expressing green fluorescent protein (GFP) (9). Five E. coli O157:H7 isolates designated 55AC1, 114AC1, 131AC1, 237AC1, and 299AB3 $(2,8)$ were used for experiments where hourly time points were taken to measure doubling time. These five strains were used in a composite preparation made by combining equal amounts of a $10^{9} \mathrm{CFU} / \mathrm{ml}$ culture, which was subsequently diluted to $10^{4} \mathrm{CFU} / \mathrm{ml}$ in buffered peptone water (BPW). Aliquots of this composite preparation were stored in glycerol stocks at $-80^{\circ} \mathrm{C}$ until use.

Bacterial growth media. Twelve bacterial growth media were selected for evaluation. The following media were selective for E. coli O157:H7: BAX System medium for E. coli O157:H7 (BAX) and BAX System medium for E. coli O157:H7 MP (BAXMP) (DuPont Qualicon, Wilmington, Del.), RapidChek E. coli O157:H7 medium (Strategic Diagnostics, Newark, Del.), Neogen Reveal for E. coli O157:H7-Eight Hour medium (Neogen Reveal 8, Neogen, Lansing, Mich.), BioControl EHEC8 culture medium (BioControl, Bellevue, Wash.), and a modified E. coli broth (mEC broth; Difco, Becton Dickinson, Sparks, Md.) with $20 \mu \mathrm{g} / \mathrm{ml}$ novobiocin. Four nonselective media (Difco, Becton Dickinson) were tryptic soy broth (TSB), BPW, Bacto-NZYM, and nutrient medium. Two media were not commercially available: SOC and buffered peptone water plus SOC (BPW-SOC). SOC was made with $10 \mathrm{~g}$ of tryptone, $5 \mathrm{~g}$ of yeast extract, and $10 \mathrm{ml}$ of $0.25 \mathrm{M}$ $\mathrm{KCl}$ to correct the $\mathrm{pH}$ to 7.0. This mixture was autoclaved and cooled to $60^{\circ} \mathrm{C}$, and then $5 \mathrm{ml}$ of sterile $2 \mathrm{M} \mathrm{MgCl}_{2}$ and $20 \mathrm{ml}$ of sterile $1 \mathrm{M}$ glucose was added. BPW-SOC was made as described for SOC with the addition of $20 \mathrm{~g} /$ liter BPW. With the exception of the SOC and BPW-SOC, all media were made according to the recommendations of the respective manufacturer.

Experiment protocol 1. Two marked strains of E. coli O157: $\mathrm{H} 7$ were used to determine the optimal growth conditions with regard to temperature $\left(37\right.$ versus $\left.42^{\circ} \mathrm{C}\right)$ and shaking or static conditions. A large sample of ground beef (80\% lean and 20\% fat) obtained from a local grocery store 24 to $48 \mathrm{~h}$ before beginning the study was inoculated with each marked strain of E. coli O157: $\mathrm{H} 7$ at $100 \mathrm{CFU} / \mathrm{g}$ by mixing the appropriate amount of bacteria with 7\% BPW (vol/wt) and thoroughly hand massaging. Ten-gram samples of inoculated ground beef were placed in $90 \mathrm{ml}$ of medium in a Whirl-Pak filter bag ( 7.5 by 12 in. [19 by $30.5 \mathrm{~cm}$ ]; Nasco, Fort Atkinson, Wis.), stomached for $1 \mathrm{~min}$ at $260 \mathrm{rpm}$ in a Lab Blender 400C (Seward Co., Essex, UK), and then incubated under selected conditions $\left(37^{\circ} \mathrm{C}\right.$ static, $37^{\circ} \mathrm{C}$ shaking, $42^{\circ} \mathrm{C}$ static, or $42^{\circ} \mathrm{C}$ shaking) for $6 \mathrm{~h}$. Samples were incubated in a Precision Scientific model 818 incubator (Thermo Electron Corp., Milford, Mass.) for static conditions or in an Innova 44 shaker incubator (New Brunswick Scientific, Edison, N.J.) with shaking at 120 $\mathrm{rpm}$. Bacteria were enumerated as described below. The growth in each medium was evaluated in a 12 (medium) $\times 4$ (growth conditions) factorial arrangement with each marked strain for a total of 48 conditions tested.

Experiment protocol 2. The composite E. coli $\mathrm{O} 157: \mathrm{H} 7 \mathrm{mix}$ was used to determine the doubling time and total CFU per milliliter during a 6-h incubation with eight of the most productive media under the optimal condition $\left(42^{\circ} \mathrm{C}\right.$ static) identified in experiment protocol 1: BPW-SOC, TSB, BAX, BAX-MP, RapidChek, Neogen Reveal 8, Bacto-NZYM, and EHEC8. Ground beef was inoculated with $\sim 2 \mathrm{CFU} / \mathrm{g}$ using the same type of ground beef ( $80 \%$ lean and $20 \%$ fat) and procedure for inoculation as described above. Ten-gram samples of inoculated ground beef were placed in $90 \mathrm{ml}$ of medium in a Whirl-Pak filter bag measuring 7.5 by $12 \mathrm{in.} \mathrm{(19} \mathrm{by} 30.5 \mathrm{~cm}$ ), stomached for $1 \mathrm{~min}$ at 260 $\mathrm{rpm}$ in a Lab Blender $400 \mathrm{C}$, and then incubated at $42^{\circ} \mathrm{C}$ static in a Precision Scientific Model 818 incubator. Bacteria were enumerated as described below. The growth in each medium was evaluated in two separate experiments to investigate the total bacterial concentration at $6 \mathrm{~h}$ and the doubling time of the composite strains in the six media tested.

Experiment protocol 3. To simulate as closely as possible the conditions of the actual test-and-hold procedure, multiple 600$\mathrm{g}$ samples of ground beef were inoculated with the 5 strain composite of E. coli $\mathrm{O} 157: \mathrm{H} 7$ at $\sim 2 \mathrm{CFU} / \mathrm{g}$, stored overnight at $4^{\circ} \mathrm{C}$, mixed together, and then divided into 375 -g samples. Each sample with medium was placed into a BagFilter bag (38 by $51 \mathrm{~cm}$, 3,500-ml volume; InterScience, St. Nom, France), stomached for $1 \mathrm{~min}$ in a Jumbo Mix lab blender (InterScience) at $260 \mathrm{rpm}$, and incubated under static conditions at $42^{\circ} \mathrm{C}$. Subsamples were collected hourly to determine doubling time and total concentration at $6 \mathrm{~h}$ using 1,2, and 3.375 liters of TSB in a 1 (medium) $\times 3$ (volume) factorial design. Bacteria were enumerated as described below.

E. coli 0157:H7 enumeration. The procedure for detection of $E$. coli $\mathrm{O} 157: \mathrm{H} 7$ was either direct plating from the different growth media (100- $\mu 1$ samples) or immunomagnetic separation of 1 -ml samples plus plating as described previously $(3,6)$. Direct plating was used for enumeration of the $131 \mathrm{AC} 1\left(\mathrm{Nal}_{50}\right)$ and GFP isolates. The $131 \mathrm{AC} 1\left(\mathrm{Nal}_{50}\right)$ strain was serially diluted and plated on tryptic soy agar (TSA; Becton Dickinson) with $50 \mathrm{mg} / \mathrm{ml} \mathrm{nal-}$ idixic acid, and colonies were counted visually after incubation at $37^{\circ} \mathrm{C}$ for $16 \mathrm{~h}$. The GFP strain was likewise serially diluted, plated on TSA, and incubated overnight at $37^{\circ} \mathrm{C}$, and colonies were counted with a model UVGL-25 UV light (254 to $365 \mathrm{nM}$; UVP, Upland, Calif.). In the second and third protocols, the five-strain composite was recovered by immunomagnetic separation and plated onto O157 selective agar (CHROMagar, DRG International, Mountainside, N.J.) supplemented with $5 \mathrm{mg} /$ liter novobiocin (Sigma, St. Louis, Mo.) and $1 \mathrm{mg} / \mathrm{liter}$ potassium tellurite. For the immunomagnetic separation, $20 \mu \mathrm{l}$ of magnetic beads coated with anti-E. coli $\mathrm{O} 157$ antibody (Dynal, Lake Success, N.Y.) was mixed with the culture for $15 \mathrm{~min}$ at room temperature with moderate shaking ( $\sim 800 \mathrm{rpm})$ on a microplate shaker. Magnetic beads were captured with a magnetic particle separation device and washed by releasing and recapturing the beads in wells containing $1 \mathrm{ml}$ of washing buffer (phosphate-buffered saline plus Tween 20). This wash step was performed twice, each time in a well with new wash buffer. The washed beads were released in a microplate well containing $50 \mu \mathrm{l}$ of the washing buffer and then plated on CHROMagar. All plates were incubated at $37^{\circ} \mathrm{C}$ for $16 \mathrm{~h}$, and bacterial colonies with the correct morphology were counted manually at each hourly time point.

Doubling time calculation. The doubling time (DT) for each medium was determined by the following formula: DT $=t / n$, where $t$ is time in minutes and $n$ is the number of generations. For this work, the doubling time was calculated over the exponential growth phase between hours 3 and 6 , which represents a total of $180 \mathrm{~min}$ (the assigned value for $t$ ). The number of gen- 
TABLE 1. Estimated number of doublings ${ }^{a}$ of two different strains of E. coli O157:H7b in 12 different media under different growth conditions ${ }^{c}$ afte 6 h of incubation

\begin{tabular}{|c|c|c|c|c|c|c|c|c|}
\hline Medium $^{d}$ & \multicolumn{4}{|c|}{ O157:H7 GFP } & \multicolumn{4}{|c|}{$131 \mathrm{AC} 1\left(\mathrm{Nal}_{50}\right)$} \\
\hline BAX & 3 & 5 & 3 & 0 & 4 & 8 & 5 & 7 \\
\hline BAX-MP & 1 & 5 & 5 & 5 & 5 & 9 & 6 & 8 \\
\hline EHEC8 & 6 & 8 & 8 & 8 & 4 & 9 & 6 & 9 \\
\hline $\mathrm{mEC}$ & 3 & 7 & 7 & 4 & 4 & 7 & 5 & 7 \\
\hline Noegen Reveal 8 & 5 & 7 & 5 & 7 & 5 & 8 & 5 & 8 \\
\hline Nutrient & 0 & 2 & 0 & 0 & 1 & 5 & 3 & 2 \\
\hline Bacto-NZYM & 2 & 7 & 5 & 6 & 5 & 9 & 6 & 8 \\
\hline RapidChek & 3 & 8 & 6 & 7 & 6 & 9 & 7 & 8 \\
\hline
\end{tabular}

${ }^{a}$ Values represent the mean number of doublings in a 6-h period rounded to the nearest whole number for triplicate samples.

${ }^{b}$ E. coli $\mathrm{O} 157: \mathrm{H} 7$ strain $131 \mathrm{AC} 1$ resistant to $50 \mu \mathrm{g} / \mathrm{ml}$ nalidixic acid $\left(131 \mathrm{AC} 1\left[\mathrm{Nal}_{50}\right]\right)$ and E. coli O157:H7 bovine field isolate transformed with a constitutive GFP-expressing plasmid.

${ }^{c}$ Growth conditions were $37^{\circ} \mathrm{C}$ static, $37^{\circ} \mathrm{C}$ shaking, $42^{\circ} \mathrm{C}$ static, and $42^{\circ} \mathrm{C}$ shaking. Shaking was at $120 \mathrm{rpm}$.

${ }^{d}$ BAX System medium for E. coli O157:H7 (BAX) and BAX System medium for E. coli O157:H7 MP (BAX-MP) (DuPont Qualicon, Wilmington, Del.), RapidChek E. coli O157:H7 medium (Strategic Diagnostics, Newark, Del.), Neogen Reveal for E. coli O157:H7Eight Hour medium (Neogen Reveal 8; Neogen, Lansing, Mich.), BioControl EHEC8 culture medium (BioControl, Bellevue, Wash.), modified E. coli (mEC) broth with $20 \mu \mathrm{g} / \mathrm{ml}$ novobiocin, tryptic soy broth (TSB), buffered peptone water (BPW), Bacto-NZYM, nutrient medium, and two media not commercially available: SOC and BPW-SOC.

erations was derived from the equation for the expression of growth by binary fission: $b=B \times 2^{n}$, where $b$ is the number of bacteria at the end of the time interval and $B$ is the number of bacteria at the beginning of the time interval. Solving for $n$ in this equation, $n=3.3 \times \log$ (number of bacteria at the end of the time interval/number of bacteria at the beginning of the time interval). The entire equation is now DT $=180 / 3.3$ (log hour $6-$ $\log$ hour 3 ) and is expressed in minutes per doubling.

Statistical analyses. Doubling time experiments were replicated seven times, and volume ratio experiments for TSB were replicated eight times. Least squares means of each sample were evaluated with the general linear model procedure of SAS statistical software (version 9.1, SAS Institute, Inc., Cary, N.C.).

\section{RESULTS AND DISCUSSION}

Growth and doubling time of E. coli O157:H7 in ground beef were examined using 12 different media (Table 1). Bacteria are known to respond differently to a variety of growth conditions (14). To evaluate each medium and condition, the growth of two strains of E. coli $\mathrm{O} 157: \mathrm{H} 7$, O157:H7 GFP and 131AC1( $\left.\mathrm{Nal}_{50}\right)$, was compared, and the results are reported as the estimated number of doublings after $6 \mathrm{~h}$ of growth. In the first experiment with the O157: H7 GFP strain, media were assessed based on bacteria achieving $\geq 5$ doublings in a 6 -h time period. In a $42^{\circ} \mathrm{C}$ static culture, bacteria grew well in 9 of the 12 media tested: BPW-SOC, Bacto-NZYM, TSB, BAX, BAX-MP, RapidChek, Neogen Reveal 8, mEC broth, and EHEC8 (Table 1). A few of the 42 and $37^{\circ} \mathrm{C}$ shaking cultures performed similarly, but in general the total concentrations were highest for bacteria grown under $42^{\circ} \mathrm{C}$ static conditions (data not shown).

In the second experiment in which the field study strain $131 \mathrm{AC} 1\left(\mathrm{Nal}_{50}\right)$ was used, a similar trend was observed in which the $42^{\circ} \mathrm{C}$ static condition was optimal (Table 1). In this experiment, the criterion for selection for further study was any condition under which $\geq 8$ doublings occurred in a 6-h time period. The difference in the number of doublings between this experiment and the first experiment can be attributed to the slower growth of the O157:H7 GFP strain compared with the $131 \mathrm{AC} 1\left(\mathrm{Nal}_{50}\right)$ strain. Others (14) have noted that some bacterial strains that express GFP grow more slowly. The fact that this strain had fewer doublings in $6 \mathrm{~h}$ emphasizes the importance of evaluating each medium under the same conditions with more than one bacterial strain (Table 1). In the second experiment, 9 of 12 media performed best under the $42^{\circ} \mathrm{C}$ static conditions: SOC, BPW-SOC, TSB, BAX, BAX-MP, RapidChek, Neogen Reveal 8, Bacto-NZYM, and EHEC8.

Media selected for further experiments to measure the doubling time and total bacterial growth in a 6-h time period were chosen based on consistent high bacterial numbers in both experiments (Table 1). BPW and SOC alone did not perform well (Table 1), but when combined the performance was superior to that of each individual medium. The optimal growth condition identified in the preliminary experiments was $42^{\circ} \mathrm{C}$ static, which matches the manufacturer's recommended conditions set forth in the protocols for Neogen Reveal 8, BAX, BAX-MP, EHEC8, and RapidChek. Incubation of samples at $42^{\circ} \mathrm{C}$ with no shaking 
TABLE 2. Effects of media on total concentration and doubling time of E. coli O157:H7 in ground beef after 6 h of incubation ${ }^{a}$

\begin{tabular}{lccc}
\hline \multicolumn{1}{c}{ Medium $^{b}$} & $\begin{array}{c}\text { Concn } \\
(\log \mathrm{CFU} / \mathrm{ml})^{c}\end{array}$ & $\begin{array}{c}\text { Doubling time } \\
(\mathrm{min})^{d}\end{array}$ & $\mathrm{SD}(\mathrm{min})^{e}$ \\
\hline BPW-SOC & $4.35 \mathrm{~A}$ & $17.2 \mathrm{~A}$ & 1.5 \\
Bacto-NZYM $_{\text {RapidChek }}$ & $4.21 \mathrm{AB}$ & $18.7 \mathrm{~A}$ & 3.0 \\
TSB & $4.17 \mathrm{AB}$ & $17.1 \mathrm{~A}$ & 0.7 \\
BAX-MP & $4.16 \mathrm{AB}$ & $17.9 \mathrm{~A}$ & 0.9 \\
EHEC8 & $4.12 \mathrm{AB}$ & $17.1 \mathrm{~A}$ & 4.0 \\
Neogen Reveal 8 & $4.03 \mathrm{BC}$ & $16.8 \mathrm{~A}$ & 2.5 \\
BAX & $3.77 \mathrm{CD}$ & $17.1 \mathrm{~A}$ & 2.9 \\
\hline
\end{tabular}

${ }^{a}$ Within a column, mean values lacking a common letter differ significantly $(P<0.05)$.

${ }^{b}$ BAX System medium for E. coli O157:H7 (BAX) and BAX System medium for E. coli O157:H7 MP (BAX-MP) (DuPont Qualicon, Wilmington, Del.), RapidChek E. coli O157:H7 medium (Strategic Diagnostics, Newark, Del.), Neogen Reveal for E. coli O157:H7-Eight Hour medium (Neogen Reveal 8; Neogen, Lansing, Mich.), BioControl EHEC8 culture medium (BioControl, Bellevue, Wash.), tryptic soy broth (TSB), BPWSOC, and Bacto-NZYM.

${ }^{c}$ Values represent mean $\log$ CFU per milliliter of seven replicates as determined by immunomagnetic separation recovery of $E$. coli $\mathrm{O} 157: \mathrm{H} 7$ from $1 \mathrm{ml}$ of sample taken at hour 6 .

${ }^{d}$ Doubling time (minutes per doubling) is calculated with the following formula: 180/3.3 $\times \log$ (hour 6/hour 3 ).

${ }^{e} \mathrm{SD}$ is the average standard deviation of doubling time from seven replicates.

was reported as the preferred growth condition (5). A temperature of $42^{\circ} \mathrm{C}$ was preferred to $37^{\circ} \mathrm{C}$ for both TSB and EC media (5).

Once the optimal growth condition $\left(42^{\circ} \mathrm{C}\right.$ static) and optimal media were identified, experiments to determine the bacterial doubling time in each medium proceeded. To remove any bias a particular medium might exhibit for a single bacterial strain, a mixture of five genetically diverse $E$. coli $0157: \mathrm{H} 7$ strains $(2,3)$ was prepared for the inoculum. The concentration (CFU per milliliter) was measured hourly for the eight media, and doubling times were calculated (Table 2). BPW-SOC resulted in the highest (log transformed) concentration, with a $30 \%$ higher cell population than that in other media (Table 2). TSB, BAX-MP, RapidChek, and Bacto-NZYM performed comparably. No significant difference was found between the BPW-SOC, TSB, BAX-MP, RapidChek, and Bacto-NZYM total concentrations at $6 \mathrm{~h}$. The bacterial concentration in EHEC8 was slightly lower than that in these five media and was significantly lower $(P<0.05)$ than that in BPW-SOC. The BAX and Neogen Reveal 8 media both performed poorly under the conditions used in this experiment, with much lower $(P<0.05)$ total concentrations at $6 \mathrm{~h}$ compared with those in BPW-SOC, Bacto-NZYM, RapidChek, TSB, and BAX-MP. The doubling time for all media, with the exception of BAX, was between 16 and $18 \mathrm{~min}$. The amount of time it took for a bacterial cell to double in BAX was $>20$ min, which was correlated with the lower concentration (Table 2) of the E. coli O157:H7 inoculum. There was no
TABLE 3. Effects of the ratio of sample to growth medium (TBS) on the total concentration and doubling time of E. coli O157:H7

\begin{tabular}{lccc}
\hline Treatment $^{b}$ & $\begin{array}{c}\text { Concn } \\
(\log \mathrm{CFU} / \mathrm{ml})^{c}\end{array}$ & $\begin{array}{c}\text { Doubling time } \\
(\mathrm{min})^{d}\end{array}$ & $\mathrm{SD}(\mathrm{min})^{e}$ \\
\hline $1: 3$ ratio & $4.59 \mathrm{~A}$ & $15.9 \mathrm{~A}$ & 2.3 \\
$1: 5$ ratio & $4.41 \mathrm{AB}$ & $17.6 \mathrm{~A}$ & 3.3 \\
$1: 10$ ratio & $4.51 \mathrm{AB}$ & $18.6 \mathrm{~A}$ & 2.9 \\
\hline
\end{tabular}

${ }^{a}$ A least squares means statistical analysis revealed no significant difference among treatments from eight replicates. Within a column, values with the same letters are not significantly different.

${ }^{b}$ The 1:3 ratio represents $375 \mathrm{~g}$ of ground beef in 1 liter of TSB, the 1:5 ratio represents $375 \mathrm{~g}$ of ground beef in 2 liters of TSB; and the 1:10 ratio represents $375 \mathrm{~g}$ of ground beef in 3.375 liters of TSB.

${ }^{c}$ Values represent mean $\log$ CFU per milliliter of eight replicates as determined by immmunomagnetic separation recovery of $E$. coli $\mathrm{O} 157: \mathrm{H} 7$ from $1 \mathrm{ml}$ of sample taken at hour 6 .

${ }^{d}$ Doubling time (minutes per doubling) is calculated with the following formula: $180 / 3.3 \times \log$ (hour 6/hour 3).

$e \mathrm{SD}$ is the average standard deviation of doubling time from eight replicates.

significant difference $(P<0.05)$ in doubling times among the eight media: TSB, BAX-MP, RapidChek, BactoNZYM, EHEC8, BPW-SOC, Neogen Reveal 8, and BAX. A larger standard deviation was observed for the data from the BAX medium. Although we did not perform experiments to investigate this result, the possibility exists that lot-to-lot variability in the starting materials may have contributed to this larger deviation. This larger standard deviation did not cause a significant difference in the doubling time in the BAX medium compared with the other seven media.

Five of the eight media performed well, leading to a review of other factors that may influence the selection of a particular growth medium. Factors included were cost, ease of use, and range of applications. BPW-SOC outperformed all media tested (Table 2). Thus, it would seem reasonable to select BPW-SOC as the optimal medium, but when the cost and ease of use are calculated, this selection is less appealing. Preparation of this medium is labor intensive, requiring $\mathrm{pH}$ adjustment before autoclaving and the addition of $\mathrm{MgCl}_{2}$ and glucose after autoclaving. The addition of more preparative steps increases the risk that the medium can be made improperly, thereby leading to falsenegative results. Of all the media tested, TSB can be used for the broadest range of applications. TSB is used for enrichments of Salmonella (4) and other bacteria $(12,13,18)$. The manufacturers' recommendations for BAX, BAX-MP, EHEC8, RapidChek, and Neogen Reveal 8 specify that these media are to be used specifically for the enrichment of E. coli, and in some cases E. coli $\mathrm{O} 157: \mathrm{H} 7$ is specified as the target organism.

TSB is inexpensive and easy to prepare and has a wide application base; it also performed well in doubling time experiments. Therefore, it was selected for further testing to determine whether the ratio of the volume of sample to the volume of medium could be reduced from the standard 
1:10 (375 g sample to 3.375 liters of medium) used currently in test-and-hold procedures. Conditions were simulated to match as closely as possible actual test-and-hold procedures. The data indicated that the normal test-and-hold of sample-to-medium ratio of 1:10 can be altered to use 1 liter of medium for each $375-\mathrm{g}$ sample tested (a 1:3 ratio) (Table 3). A least squares means statistical analysis of the eight replicates per treatment revealed no significant difference in total bacterial concentration at $6 \mathrm{~h}$ and in bacterial doubling time between any of the three volumes tested. Alteration of the $1: 10$ ratio to $1: 3$ would result in a significant cost savings for growth medium, and sample incubation would require less space and would be less cumbersome.

The doubling time for E. coli $\mathrm{O} 157: \mathrm{H} 7$ was compared for 12 different media; growth in five of those media was not significantly different (doubling time and total bacterial concentration after $6 \mathrm{~h}$ ). The superiority of TSB for use in the test-and hold process was documented. Based on this analysis, 1 liter, rather than the conventional 3.375 liters, of medium can be used to enrich $375 \mathrm{~g}$ of ground beef.

\section{ACKNOWLEDGMENTS}

We thank Kim Kucera for her technical support, Drs. Joseph M. Bosilevac and Norasak Kalchayanand for their critical review of the manuscript, and Marilyn Bierman and Carol Grummert for their secretarial skills.

\section{REFERENCES}

1. Arthur, T. M., J. M. Bosilevac, X. Nou, and M. Koohmaraie. 2005. Evaluation of culture- and PCR-based detection methods for Escherichia coli $\mathrm{O} 157$ in ground beef. J. Food Prot. 68:1566-1574.

2. Barkocy-Gallagher, G. A., T. M. Arthur, G. R. Siragusa, J. E. Keen, R. O. Elder, W. W. Laegreid, and M. Koohmaraie. 2001. Genotypic analyses of Escherichia coli O157:H7 and O157 nonmotile isolates recovered from beef cattle and carcasses at processing plants in the Midwestern states of the United States. Appl. Environ. Microbiol. 67:3810-3818.

3. Barkocy-Gallagher, G. A., E. D. Berry, M. Rivera-Betancourt, T. M. Arthur, X. Nou, and M. Koohmaraie. 2002. Development of methods for the recovery of Escherichia coli O157:H7 and Salmonella from beef carcass sponge samples and bovine fecal and hide samples. $J$. Food Prot. 65:1527-1534.

4. Barkocy-Gallagher, G. A., D. H. Kang, and M. Koohmaraie. 2002. Fate of field-isolated Escherichia coli $\mathrm{O} 157$ in ground beef at different storage temperatures. J. Food Prot. 65:1106-1109.

5. Blais, B. W., R. A. Booth, L. M. Phillippe, and H. Yamazaki. 1997. Effect of temperature and agitation on enrichment of Escherichia coli $\mathrm{O} 157: \mathrm{H} 7$ in ground beef using modified EC broth with novobiocin. Int. J. Food Microbiol. 36:221-225.

6. Bosilevac, J. M., S. D. Shackelford, D. M. Brichta, and M. Koohmaraie. 2005. Efficacy of ozonated and electrolyzed oxidative waters to decontaminate hides of cattle before slaughter. J. Food Prot. 68: 1392-1398

7. Brabban, A. D., D. A. Nelsen, E. Kutter, T. S. Edrington, and T. R. Callaway. 2004. Approaches to controlling Escherichia coli O157: H7, a foodborne pathogen and an emerging environmental hazard. Environ. Rev. 6:208-229.

8. Elder, R. O., J. E. Keen, G. R. Siragusa, G. A. Barkocy-Gallagher, M. Koohmaraie, and W. W. Laegreid. 2000. Correlation of enterohemorrhagic Escherichia coli $\mathrm{O} 157$ prevalence in feces, hides, and carcasses of beef cattle during processing. Proc. Natl. Acad. Sci. USA 97:2999-3003.

9. Fratamico, P. M., M. Y. Deng, T. P. Strobaugh, and S. A. Palumbo. 1997. Construction and characterization of Escherichia coli O157: H7 strains expressing firefly luciferase and green fluorescent protein and their use in survival studies. J. Food Prot. 60:1167-1173.

10. Koohmaraie, M., T. M. Arthur, J. M. Bosilevac, M. Guerini, S. D. Shackelford, and T. L. Wheeler. 2005. Post-harvest interventions to reduce/eliminate pathogens in beef. Meat Sci. 71:79-91.

11. Naugle, A. L., K. G. Holt, P. Levine, and R. Eckel. 2005. Food Safety and Inspection Service regulatory testing program for Escherichia coli O157:H7 in raw ground beef. J. Food Prot. 68:462-468.

12. Norwood, D. E., and A. Gilmour. 2000. The growth and resistance to sodium hypochlorite of Listeria monocytogenes in a steady-state multispecies biofilm. J. Appl. Microbiol. 88:512-520.

13. Pfaller, M. A., L. M. Westfall, A. C. Niles, A. Kinroth, and P. R. Murray. 1983. Comparison of tryptic soy broth with tryptic soy broth supplemented with sucrose in the Septi-Chek blood culture system. J. Clin. Microbiol. 17:272-275.

14. Rang, C., J. E. Galen, J. B. Kaper, and L. Chao. 2003. Fitness cost of the green fluorescent protein in gastrointestinal bacteria. Can. J. Microbiol. 49:531-537.

15. Riley, L. W., R. S. Remis, S. D. Helgerson, H. B. McGee, J. G. Wells, B. R. Davis, R. J. Hebert, E. S. Olcott, L. M. Johnson, N. T. Hargrett, P. A. Blake, and M. L. Cohen. 1983. Hemorrhagic colitis associated with a rare Escherichia coli serotype. N. Engl. J. Med. 308:681-685.

16. Taylor, M. 1994. Change and opportunity: harnessing innovation to improve the safety of the food supply. Presented at the American Meat Institute Annual Convention, San Francisco, Calif., 29 September 1994.

17. Tuttle, J., T. Gomez, M. P. Doyle, J. G. Wells, T. Zhao, R. V. Tauxe, and P. M. Griffin. 1999. Lessons from a large outbreak of Escherichia coli O157:H7 infections: insights into the infectious dose and method of widespread contamination of hamburger patties. Epidemiol. Infect. 122:185-192.

18. Walker, S. J., and A. Gilmour. 1986. A comparison of media and methods for the recovery of Yersinia enterocolitica and Yersinia enterocolitica-like bacteria from milk containing simulated raw milk microfloras. J. Appl. Bacteriol. 60:175-183. 